1

\title{
DIMENSIONAL VARIATION OF THREE SOFTWOOD DUE TO HYGROSCOPIC BEHAVIOR
}

2

Keywords: Dimensional variations; equilibrium moisture content; shrinkage; swelling
Catarina Silva ${ }^{\mathrm{a}}$, Jorge M. Branco ${ }^{\mathrm{b}}$, Aires Camões ${ }^{\mathrm{c}}$, Paulo B. Lourenço ${ }^{\mathrm{d}}$

${ }^{a} \mathrm{PhD}$ student, ISISE, Univ. of Minho, Dept. of Civil Engineering E-mail: catarinasilva@,civil.uminho.pt

${ }^{\mathrm{b}}$ Assistant Professor, ISISE, Univ. of Minho, Dept. of Civil Engineering, Campus de Azurém, 4810-058 Guimarães, Portugal.

Tel. +351 253510 200; Fax: +351253510217

E-mail: ibranco@civil.uminho.pt; Corresponding author

${ }^{c}$ Assistant Professor, C-TAC, Univ. of Minho, Dept. of Civil Engineering E-mail: aires@civil.uminho.pt

${ }^{\mathrm{d}}$ Full Professor, ISISE, Univ. of Minho, Dept. of Civil Engineering E-mail: pbl@civil.uminho.pt
Abstract: With the aim of monitor the hygroscopic behavior of three softwood species in situations of changes in its moisture content, an experimental program based on dimensional measurements, hygrometer readings and weightings procedure, was carried out. Maritime Pine (Pinus pinaster), Spruce (Picea abies) and Scots Pine (Pinus sylvestris) specimens were evaluated and compared. For each wood species, half of specimens were previously dried while the other half was previously saturated. Three main variables studied during the period of specimen's adjustment to an external environment of $20^{\circ} \mathrm{C}$ and $57.5 \%$ relative humidity $(\mathrm{RH})$ were: mass, dimensional and moisture content variations. Based on the obtained experimental results, the equilibrium moisture content, as well as coefficients of linear shrinkage and expansion, were determined. Experimental results confirmed that besides RH and temperature, the equilibrium moisture content of wood depends on its moisture history. Moreover, using the obtained values it was possible to identify differences between the hygroscopic behavior of the softwood species studied. 


\section{Introduction}

Wood is a natural and renewable resource, with significant applications in material production, building construction and civil engineering. In use, wood is jointly subjected to mechanical and moisture loads and inappropriate loading of wood can result in mechanical damage and biodegradation.

The amount of moisture, or water, in wood depends on the surrounding climate. After harvesting and in the absence of direct contact with liquid water, the moisture content of wood is controlled by temperature $(\mathrm{T})$ and relative humidity $(\mathrm{RH})$. Wood is constantly gaining and losing moisture from or to the surrounding air until an equilibrium point is reached, called equilibrium moisture content (EMC).

Owing to the cellular structure of wood, water can be held in two ways: (1) free water in the cell cavities, and (2) chemically bounded water in the cell walls. In the drying process of wood after harvest, the removal of free-water occurs first, with no change either in dimension or in physical and mechanical properties of wood. At the state where no free-water is present in the cell cavity and the cell wall is fully saturated with bounded water, the cell is said to be at the fiber-saturation point (FSP). For practical purposes, this level of moisture content is generally considered around $25-30 \%$, but it may be significantly different among wood species [1]. The variation of moisture content below the FSP is accompanied by changes on both physical (dimensional variation) and mechanical properties [2]. During desorption the specimen undergoes shrinkage, whilst during absorption the specimen swells.

52 Macroscopically, this process can be quantified by the volumetric or linear shrinkage coefficient: radial $53\left(k_{r}\right)$, tangential $\left(k_{t}\right)$ and longitudinal $\left(k_{l}\right)$. Moreover, the shrinkage process is direction dependent: $k_{t} \gg$ $54 \quad k_{r} \gg k_{l}$. This anisotropy is the origin for relevant distortions on the shape of wood pieces.

Furthermore, changes in the moisture content below the FSP also result in variations in the 56 mechanical properties of wood. In practice, a linear relationship between elastic modulus of wood and moisture content can be assumed within a range of $8-20 \%$ [3]. methods use oriented small wood specimens. For measuring volumetric changes generated by moisture content variations below the FSP the immersion method is proposed. On the other hand, radial and

61 tangential shrinkage are determined by measuring changes on dimensions with accuracy not less than $620.02 \mathrm{~mm}$. 
63 Aside recommended standards used for present research, it is important to mention that new 64 image-based measurement methods, such as digital image correlation (DIC) have been developed [9]$65[10]$. This recent contact free technique was already used in some published researches for determination 66 of shrinkage coefficients [11-12].

67 Important research efforts have been made on the use of high temperature in the drying process 68 with the purpose to reduce wood hygroscopicity [13-14]. There are studies regarding prediction models 69 for wood moisture content and density [15], and studies that explore variations of moisture content at 70 different temperatures and relative humidity, in order to understand wood hygroscopic behavior and enable comparisons between different species and also within the same species [16-18].

73 determine the equilibrium condition of wood species in different environments. This knowledge is 74 important to predict the performance of wood elements during their life-time. Moreover, data from the 75 equilibrium condition of wood and the magnitude of the shrinkage and swelling coefficients allows taking 76 into account design measures to predict and avoid cracks and induced stresses. The development of 77 cracks reduces the market value of the wood elements and can decrease significantly its performance 78 from a structural point of view, in particular, if located near the joints.

79 This study is focused on understanding and comparing the relation between dimensional variation 80 and moisture content of three softwoods largely applied in the European construction sector, namely

81 Maritime Pine (Pinus pinaster), Spruce (Picea abies) and Scots Pine (Pinus sylvestris).

\section{2. Experimental program}

\section{$84 \quad 2.1$ Specimens and Test Configuration}

85 Two experimental campaigns were performed in order to monitor shrinkage and swelling behavior 86 of the three softwoods selected. One tested 220 specimens: eighty of Maritime Pine, eighty of Spruce and 87 sixty of Scots Pine. The other one tested a total of sixty wood specimens: twenty specimens of each 88 species.

89 Specimens have dimensions of $50(\mathrm{R}) \times 50(\mathrm{~T}) \times 10(\mathrm{~L}) \mathrm{mm}^{3}$, in which $\mathrm{R}, \mathrm{T}$ and $\mathrm{L}$ stands for radial, 90 tangential and longitudinal orthotropic directions. 
Both experimental campaigns aimed to understand the shrinkage and swelling behavior, under controlled conditions, of maritime pine, spruce and scots pine. To analyze the shrinkage behavior specimens were saturated, while to analyze the swelling behavior specimens were oven dried. For both

94 experimental campaigns, before start test program, half of specimens of each species were dried (D) while 95 the other half was saturated (S). Drying process was made using an oven at $103^{\circ} \mathrm{C}+/-2^{\circ} \mathrm{C}$ until obtaining constant mass. Saturation was obtained after submersion of specimens in a water tank, during a period of 2 weeks, ensuring that the specimens had constant mass [5]. Mass was considered constant when the difference between two successive weight measurements, spaced by 2 hours, was less than $0.5 \%$ [19].

After imposing these two different starting conditions, all specimens were placed in a climatic chamber (FITOCLIMA 28000 EDTU from ARALAB) with constant environmental conditions of $20^{\circ} \mathrm{C}$ and $57.5 \%(\mathrm{RH})$ until reach stabilization of specimens.

The stabilization process was considered complete when dimensional variation of specimens was less than $0.5 \%$ in a period of 12 hours. Although the three softwoods studied had different speeds of stabilization, all specimens remained inside the climatic chamber until the three softwoods were considered stable. Dimensional and weight variations were collected during the stabilization processes, respecting pre-defined periods of time, until the equilibrium moisture content was attained.

The measurement system for dimensions was constituted by a metal base that supported a standard-dial gauge (with a precision of $1 \mu \mathrm{m}$ ), in order to ensure the accuracy of measurements. Four metal bases were made; three of them were used to measure continuously one single specimen, one of each wood species, while the other one was used for measuring all remaining specimens. The readings obtained by the three fixed metal bases served to confirm the accuracy of the measurement collected by moisture content readings were also made using a hygrometer (CSA ELECTRONIC - DELTA -8N). The

117 goal was to evaluate the accuracy of the hygrometer readings in comparison with the oven dry method 118 suggested by [19]. However it is important to consider the fact that hygrometer readings are only reliable 119 for moisture contents between 8-24\% [20], providing large errors in the case of higher moisture content 
values. In this way, the comparison between these two measuring techniques was limited to moisture content values bellow the FSP.

\subsection{Test development} related with test development: the period of stabilization (1) and spacing between readings (2). Campaign with larger sample has a larger stabilization period (96 hours) with spacing of 12 hours between dimension readings and 24 hours for weight and moisture content readings. Smaller campaign submitted dried and saturated specimens to stabilization periods of 29 and 78 hours, respectively. Spacing of of 42 hours.

131 The option to perform a campaign with smaller reading intervals during a smaller stabilization period is based on the fact that dimensional and moisture content variations are substantially larger during

133 the first 36 hours of test in case of saturated specimens and during the first 12 hours in case of dried

134 specimens. Further, smaller periods allowed a better observation of dimensional variation in first hours of 135 stabilization period and allowed determining more accurately the relation between moisture content and linear shrinkage/swelling, in radial and tangential directions.

In addition to these differences, experimental campaign with smaller sample evaluated the

138 consequences of a full humidity cycle on the swelling capacity of wood through the comparison between

139 only dried [OD] specimens and specimens dried after a saturation process [SD]. For that, after the

140 stabilization process of the saturated specimens, the same specimens were dried and submitted to another

141 stabilization process, as suggested in [4]-[5].

142

\section{3. Results and discussion}

\section{3.1. Larger experimental campaign}

145 Figure 2 presents graphically the evolution of average values of linear shrinkage $(\beta)$ and swelling

$146(\alpha)$ of saturated and dried specimens in radial and tangential directions $\left(\beta_{r}, \alpha_{r}, \beta_{t}\right.$ and $\alpha_{t}$, respectively).

147 Linear shrinkage and swelling values were calculated based on formulas (1) and (2) suggested in [4][5]. 


$$
\beta=\frac{l_{\max }-l_{\min }}{l_{\max }} \times 100
$$

where $l_{\text {max }}$ is the dimension of saturated specimens, in radial or tangential direction, in mm, and $l_{\min }$ is the dimension of specimens at time of measurement, in radial or tangential direction, in $\mathrm{mm}$.

$$
\alpha=\frac{\mathrm{l}_{\max }-\mathrm{l}_{\min }}{\mathrm{l}_{\min }} \times 100
$$

where $l_{\text {max }}$ is the dimension of specimens at time of measurement, in radial or tangential direction, in $\mathrm{mm}$, and $l_{\min }$ is the dimension of oven dried specimens, in radial or tangential direction, in $\mathrm{mm}$.

At the end of shrinkage period of saturated specimens, obtained $\beta_{r}$ values were: $0.80 \%$ 151 Pine, respectively. Considering the same order obtained $\beta_{t}$ values were: $1.87 \%(\mathrm{CoV}=6.1 \%), 3.68 \%$ $152(\mathrm{CoV}=6.6 \%)$ and $2.77 \%(\mathrm{CoV}=18.1 \%)$.

Relatively to dried specimens obtained swelling values $\alpha_{r}$ were: $1.07 \%(\mathrm{CoV}=9.5 \%), 2.04 \%$ $154(\mathrm{CoV}=6.0 \%)$ and $1.75 \%(\mathrm{CoV}=11.1 \%)$ for Maritime Pine, Spruce and Scots Pine, respectively. 155 Considering the same order obtained $\alpha_{t}$ values were: $1.56 \%(\mathrm{CoV}=6.9 \%), 3.22 \%(\mathrm{CoV}=6.6 \%)$ and $1562.26 \%(\mathrm{CoV}=11.8 \%)$. From 0 to 24 hours the decrease of moisture content of saturated specimens was significant for all three wood species: from $127.4 \%$ to $21.0 \%$, from $154.3 \%$ to $16.7 \%$ and from 113.2 to $19.1 \%$ for Scots Pine, Spruce and Maritime Pine, respectively. During this first 24 hours, saturated specimens had 160 presented results for $\beta_{r / t}$ and $\alpha_{r / t}$ with a very high Coefficient of Variation (CoV) (30\% and higher). It is 161 possible to speculate that high $\mathrm{CoV}$ values are related with different levels of saturation between 162 specimens. Due to the heterogeneity of wood maybe different specimens have different shrinkage 163 velocities. Following this idea, when specimens are forced to shrink rapidly the difference between their 164 behavior can be emphasized. Furthermore, during saturation process, different levels of absorption may 165 result in different levels of saturation of specimens, exacerbating the difference of behavior between 166 specimens during first 24 hours of stabilization. But more research is needed for a definitive conclusion. Relatively to dried specimens, they present lower $\mathrm{CoV}$ values once dimensional variations are 168 smaller and the oven-dry process guaranteed that all specimens began the stabilization process in an 169 anhydrous state.

170 Despite the high CoV values, results prove their reliability through values representative of wood 171 anisotropy, which match with values suggested by bibliography (a ratio between tangential and radial 
172 shrinkage $\left(A=\frac{\beta_{t}}{\beta_{r}}\right.$ around 2) [1]. Spruce and Maritime Pine specimens presented the higher $A$ values,

1732.29 and 2.34, respectively, while, Scots Pine achieved a $A$ value of 1.96.

Figure $2 \mathrm{a}$ and $\mathrm{b}$ shows that the swelling became stable at the end of 24 hours of measurements for all wood species in both measured directions. Relatively to shrinkage (Figure 2c and d), results obtained for both measured directions and three wood species show the same trend towards stabilize after the first 48 hours.

Figure 3 exhibits the comparison between the wood moisture content values obtained through the oven dry method [19] and by hygrometer readings. As expected, for the relevant range (8-24\%), hygrometer shows to be effective in the prediction of the moisture content for the three softwoods studied, presenting always slightly lower values in comparison to the oven dry method.

\subsection{Smaller experimental campaign}

In a general ways results obtained for linear shrinkage and swelling in both directions were a bit higher than values obtained for larger experimental campaign. Despite the differences between two experimental campaigns, similar conclusions were taken from results: Maritime Pine and Spruce have the higher ratio between tangential and radial anisotropy (2.34); Spruce has the larger values for linear shrinkage $\left(\beta_{r}=2.72 \%(\mathrm{CoV}=9.2 \%)\right.$ and $\left.\beta_{t}=4.92 \%(\mathrm{CoV}=10.4 \%)\right)$ and for linear swelling $\left(\alpha_{r}=2.24 \%\right.$ $(\mathrm{CoV}=9.0 \%)$ and $\left.\alpha_{t}=3.60 \%(\mathrm{CoV}=5.8 \%)\right)$; in opposition to Maritime Pine which presents the lower values: $\beta_{r}=1.31 \% \quad(\mathrm{CoV}=26.4 \%), \beta_{t}=2.58 \% \quad(\mathrm{CoV}=23.7 \%), \alpha_{r}=1.09 \% \quad(\mathrm{CoV}=7.3 \%)$ and $\alpha_{t}=1.89 \%$ $(\mathrm{CoV}=4.9 \%)$

Figure 4 depicts $\beta_{r}, \beta_{t}, \alpha_{r}$ and $\alpha_{t}$ along time obtained from the smaller experimental campaign, demonstrating that smaller reading intervals improve the assessment of dimensional variation. Dried specimens had the greater variations during first 2 hours and saturated specimens had the greater variations between 19 and 29 hours (period in which the moisture content becomes smaller than FSP). As noted in the previous phase, saturated specimens had presented high $\mathrm{CoV}$ values $(30 \%$ and higher) until reach lower levels of moisture content. As shown in Figure 5, with these smaller reading periods it was possible to relate higher $\mathrm{CoV}$ values with moisture levels higher than FSP.

Afterwards, the methodology proposed in [4] was followed, submitting specimens to a complete humidity cycle. This procedure allowed calculating maximum linear shrinkage, in radial and tangential 
201 directions, and maximum volumetric shrinkage $\left(\beta_{r, \max }, \beta_{t, \max }\right.$ and $\beta_{v, \max }$, respectively). Linear and 202 volumetric shrinkage were calculated through equations (1) and (3) as recommended in [4],[6]. To obtain 203 maximum linear shrinkage, $l_{r / t, \min }$ presented in formula (1) represents the dimension of oven dried specimens.

$\beta_{v, \max }=\frac{\left(l_{t, \max } x l_{r, \max }\right)-\left(l_{t, \min } \times l_{r, \min }\right)}{l_{t, \max } x l_{r, \max }}$

where $l_{t, \max }$ is the dimension of saturated specimens in tangential direction, in $\mathrm{mm}, l_{r, \max }$ is the dimension of saturated specimens in radial direction, in $\mathrm{mm}$ and $l_{t, \min }$ is the dimension of oven dried in tangential direction, in $\mathrm{mm}$, and $l_{r, \min }$ is the dimension of oven dried in radial direction.

It is important to refer that as dimension of specimens on longitudinal direction are so small, their longitudinal direction is in the amount of $0.1-0.4 \%$, while in radial and tangential directions variability is more significant, $3.0-6.0 \%$ and $6.0-12.0 \%$, respectively [21].

Table 1 presents the main results of the second experimental phase namely, linear shrinkage, in

211 tangential and radial directions $\left(\beta_{t, \max }\right.$ and $\beta_{r, \text { max }}$, respectively), coefficient of linear shrinkage $\left(k_{t}\right.$ and $212 k_{r}$, respectively), volumetric shrinkage $\left(\beta_{v, \max }\right)$, and coefficient of volumetric shrinkage $\left(k_{v}\right)$. 213 Coefficients of linear shrinkage were calculated with the ratio between $\left(l-l_{\min }\right) /\left(l_{\min } x W\right)$, in which $l$

214 is the dimension of specimen at the end of shrinkage process, $l_{\min }$ is the dimension of oven dried 215 specimen and $W$ is the moisture content of specimen also at the end of shrinkage process with moisture 216 content values between $13-15 \%$. Coefficient of volumetric shrinkage was calculated similarly using the 217 volumetric dimensions of specimens.

218 The results obtained for both linear shrinkages in the case of Maritime Pine and Scots Pine 219 specimens were lower than the values collected in literature. Awoyemi [18] reported that linear shrinkage 220 of Scots Pine is $6.14 \%$ and $8.29 \%$, while this study shows values of $4.32 \%(\mathrm{CoV}=19.6 \%)$ and $6.97 \%$ $221(\mathrm{CoV}=13.3 \%)$ in radial and tangential direction, respectively. Pinto [22] reported a radial linear shrinkage 222 for Maritime Pine of 5.0\% and $8.5 \%$ for the tangential linear shrinkage, while the present experimental 223 program obtained values of $2.75 \%(\mathrm{CoV}=18.6 \%)$ and $5.45 \%(\mathrm{CoV}=21.7 \%)$, in radial and tangential 224 direction, respectively. However, for Spruce the results obtained were within the expected range from the 225 literature. Gryc et al [21] indicate a range of values for Spruce: radial shrinkage should be between $4.23 \%$ 226 and $5.70 \%$ and tangential shrinkage should be between $7.16 \%$ and $10.36 \%$. The results of present study 
are within this range presenting values of $5.55 \%(\mathrm{CoV}=6.1 \%)$ and $10.05 \%(\mathrm{CoV}=9.0 \%)$, in radial and tangential direction, respectively. Despite the differences between the results obtained in this experimental program and those reported by some literature for Maritime Pine and Scots Pine, the ratios between the tangential and radial shrinkage are similar to the value suggested by literature in all cases, (shrinkage or swelling), EMC was calculated with the average of final moisture content values of dried and saturated specimens. FSP was calculated through volumetric shrinkage values.

$$
F S P=\frac{\beta_{v, \max }}{\sigma_{v}}
$$
an FSP around 30\%. Maritime Pine has the highest EMC (12.8\%) and highest FSP (32.7\%) while Scots Pine has the lower values (12.1\% and 26.6\%, respectively). Spruce has an EMC of $12.2 \%$ and a FSP of $30.4 \%$.

Differently to values obtained for dimensional variation and linear shrinkage, density of reference and moisture content presents lower and more constant values for coefficients of variance $(\mathrm{CoV})$. Density of reference was obtained through the methodology and formula suggested in [24]:

$\rho_{12}=\rho_{\mathrm{W}}\left[1-\frac{(1-\mathrm{k})(\mathrm{w}-12)}{100}\right]$

$\rho_{12}$ is the specimen density with $\mathrm{W} \%$ of moisture content, $\mathrm{W}$ is the moisture content of specimens, in percentage and $k$ is the coefficient of volumetric shrinkage. 
The three softwoods studied have quite different reference values for the density, but all of them 253 are within the range established by the literature $\left(0.32-0.72 \mathrm{~g} / \mathrm{cm}^{3}\right)$ [1]. Maritime Pine is the heaviest one 254 with a density of reference of $0.659 \mathrm{~g} / \mathrm{cm}^{3}(\mathrm{CoV}=2.0 \%)$; Spruce is the lightest with a density of reference 255 of $0.470 \mathrm{~g} / \mathrm{cm}^{3}(\mathrm{CoV}=1.2 \%)$; and Scots Pine has a density close of Spruce with a density of reference of $2560.502 \mathrm{~g} / \mathrm{cm}^{3}(\mathrm{CoV}=1.6 \%)$.

To assess the possibility that wood suffers irreversible changes on their ability to shrink/swell after consecutive shrinkage/swelling processes, a comparison between OD specimens and SD specimens was performed. Figure 6 shows that besides RH and temperature, the EMC of wood depends on its moisture

\section{CONCLUSIONS}

As a hygroscopic material, wood responds to changes in environmental humidity by changing its geometry, i.e. it swells during wetting and shrinks during drying, until EMC is not reached. The experimental work developed confirms that EMC of wood depends on $\mathrm{RH}$, temperature and its moisture history. As expected, saturated specimens have the greater variations between 24 and 36 hours (when the moisture content becomes lower than FSP) while dried specimens presented most of the geometric variation during the first 12 hours due to the higher capacity of wood absorb water when it is in the anhydrous state.

Analyzing the results of both experimental campaigns, the following main conclusions can be pointed out: 
- Maritime Pine is the wood species with lower ability to shrink and swell $\left(k_{v}=0.24 \%\right)$, higher EMC (12.8\%) and FSP (32.7\%). It is the heaviest wood specie with a reference density value of $0.659 \mathrm{~g} / \mathrm{cm}^{3}$;

- Spruce is the more sensitive to shrink and swell $\left(k_{v}=0.51 \%\right)$ wood specie, and it is the lightest one with a density of reference of $0.470 \mathrm{~g} / \mathrm{cm}^{3}$;

- There is a relation between density and dimensional variation of wood: the lightest wood species have demonstrated large shrinkage/swelling ability;

\section{ACKNOWLEDGEMENTS}

295 The financial support of the Portuguese Science Foundation (Fundação de Ciência e Tecnologia, FCT),

296 through PhD grant SFRH / BD / 79972 / 2011 is gratefully acknowledged. 
299 [1]. FPL. Wood Handbook. Technical Report FPL-GTR-113, U.S. Department of Agriculture, Forest

$300 \quad$ Service, Forest Products Laboratory, 1999.

301 [2]. Simpson W., TenWold A., Physical properties and moisture relations. In F. P. Laboratory, Wood

[3]. Green, D. W., Kretschmann, D. E. (1994) Moisture content and the properties of clear southern pine. Res. Pap. FPLRP-531, US Department of Agriculture, Forest Service, Forest Products Laboratory, Madison, WI, USA.

[4]. ISO/TC 4469:1981: Wood - Determination of radial and tangential shrinkage. International Organization for Standardization, Switzerland, 1981.

[5]. ISO/TC 4859:1982: Wood - Determination of radial and tangential swelling. International Organization for Standardization, Switzerland, 1982.

[6]. ISO/TC 4858:1982: Wood - Determination of volumetric shrinkage. International Organization for Standardization, Switzerland, 1982.

[7]. ISO/TC 4860:1982: Wood - Determination of volumetric swelling. International Organization for Standardization, Switzerland, 1982.

[8]. ASTM D143-94, Standard methods of testing small clear specimens of timber. American Society for Testing and Materials, Philadelphia, PA, USA, 1994.

[9]. Pan, B.; Qian, K.; Xie, H. \& Asundi, A. Two-dimensional digital image correlation for in-plane displacement and strain measurement: a review. Measurement Science and Technology, 2009, 20

[10].Xavier, J.; de Jesus, A.; Morais, J. \& Pinto, J. Stereovision measurements on evaluating the modulus of elasticity of wood by compression tests parallel to the grain. Construction and Building Materials, 2012, 26, 207-215.

[11].Keunecke, D.; Novosseletz, K.; Lanvermann, C.; Mannes, D. \& Niemz, P. Combination of X-ray and digital image correlation for the analysis of moisture-induced strain in wood: opportunities and challenges. European Journal of Wood and Wood Products, 2012, 70, 407-413.

[12]. Hansmann, C.; Konnerth, J. \& Rosner, S. Digital image analysis of radial shrinkage of fresh spruce (Picea abies L.) wood Wood. Material Science and Engineering, 2011, 6, 2-6. 
[13].Garcia E.L., Garcia F.F., Guindeo C.A., Palacios D.P., \& Gril J., Comparison of the hygroscopic behaviour of 205-year-old and recently cut juvenile wood from Pinus sylvestris L. C INRA, EDP Sciences, 2006, 309-317.

[14].Sik H., Khengten C., The Influence of Drying Temperature on the Hygroscopicity of Rubberwood (Hevea Brasiliensis). Journal of Agricultural Science, 2 (I), 2010, 48-58.

[15].Johansson J., Hagman O., Oja J., Predicting moisture content and density of Scots pine by microwave scanning of sawn timber. Computers and Electronics in Agriculture, 41, 2003, 85-90.

[16].Machado N., Variação dimensional da madeira e o seu comportamento higroscópico. Tese de Mestrado. Faculdade de Engenharia da Universidade do Porto, Porto, 2006.

[17]. Sousa V.B., Leal S., Pereira H., Avaliação de algumas propriedades físicas da madeira de sobreiro (Quercus suber L.) tendo em vista o seu potencial impacto tecnológico. $5^{\circ}$ Congresso Florestal Nacional - A Floresta e as Gentes, Sociedade Portuguesa de Ciências Florestais, Viseu, 2005.

[18].Awoyemi L., Reversibility of dimensional changes in birch (Betula Pubescens) and scots pine (Pinus Sylvestris L.) wood. Taiwan J For Sci, 19 (2), 2003, 97-101.

[19].ISO/TC 3130:1975: Wood - Determination of moisture content for physical and mechanical tests.

[20].Forsén H., Tarvainen V., Accuracy and functionality of hand hel wood moisture content meters. Technical Research Center of Finland. VTT publications 420. 79p. + app. 17p.. Espoo 2000.

[21].Gryc V., Vavrčík H., Horáček P., Variability in swelling of spruce (Picea abies [L.] Karst.) wood with the presence of compression wood. Journal of forest science, 53 (6), 2007, 243-252.

[22].Pinto I., Raw Material Characteristics of Maritime Pine (Pinus pinaster Ait.) and their influence on simulated sawing yield. VTT Publications 533. 51p. + app. 69p.. Espoo 2003.

[23].Carvalho A.D., Madeiras Portuguesas. Estrutura anatómica. Propriedades. Utilizações. Instituto Florestal, Vol. I, Lisboa, 2006.

[24].ISO/TC 3131:1975: Wood - Determination of density for physical and mechanical tests.

[25].Hoffmeyer P., Thygesen L. G. and Engelund E. T., Equilibrium moisture content in Norway spruce during the first and second desorptions. Holzforschung 65:875-882, 2011. 
Click here to download Table: tables.docx

\section{TABLE CAPTIONS}

Table 1 - Main results obtained derived from the second phase of the experimental program (average values) 
Table 1 - Main results obtained derived from the second phase of the experimental program (average values)

\begin{tabular}{lcccccc}
\hline \hline Softwood species & $\begin{array}{c}\boldsymbol{\beta}_{\boldsymbol{t} \text { max }} \\
{[\%]}\end{array}$ & $\begin{array}{c}\boldsymbol{\beta}_{\boldsymbol{r}, \max } \\
{[\%]_{\mathbf{r}}}\end{array}$ & $\begin{array}{c}\boldsymbol{k}_{\boldsymbol{t}} \\
{[\%]}\end{array}$ & $\begin{array}{c}\boldsymbol{k}_{\boldsymbol{r}} \\
{[\%]}\end{array}$ & $\begin{array}{c}\boldsymbol{\beta}_{\boldsymbol{v}, \max } \\
{[\%]}\end{array}$ & $\begin{array}{c}\boldsymbol{k}_{\boldsymbol{v}} \\
{[\%]}\end{array}$ \\
\hline \hline Maritime Pine (MP) & 5.45 & 2.75 & 0.17 & 0.07 & 8.30 & 0.24 \\
\hline Spruce (S) & 10.05 & 5.55 & 0.31 & 0.19 & 13.91 & 0.51 \\
\hline Scots Pine (SP) & 6.97 & 4.32 & 0.25 & 0.17 & 10.38 & 0.43 \\
\hline
\end{tabular}




\section{FIGURE CAPTIONS}

Fig. 1: Fixed and non-fixed measurement systems.

Fig. 2: Linear shrinkage $(\beta)$ and swelling $(\alpha)$ in time in radial and tangential directions of larger experimental campaign with standard deviation bars. (a) dried specimens [D] in radial direction; (b) dried specimens [D] in tangential direction; (c) saturated specimens [S] in radial direction (d) saturated specimens $[\mathrm{S}]$ in tangential direction

Fig. 3: Reliability of hygrometer when compared with weighing (

Fig. 4: Linear Shrinkage $(\beta)$ and Swelling $(\alpha)$ in time in radial and tangential directions calculated during smaller experimental campaign, with standard deviation bars. (a) only dried specimens [D] in radial direction; (b) only dried specimens [D] in tangential direction; (c) saturated and dried specimens when saturated $[\mathrm{S}]$ in radial direction (d) saturated and dried specimens when saturated $[\mathrm{S}]$ in tangential direction

Fig. 5: Moisture content (W) and its relation with time

Fig. 6: Evolution of linear swelling in time representing loose of elastic capacity of wood when dried after saturation. (a) Maritime Pine in radial direction; (b) Maritime Pine in tangential direction; (c) Spruce in radial direction; (d) Spruce in tangential direction; (e) Scots Pine in radial direction; (f) Scots Pine in tangential direction 


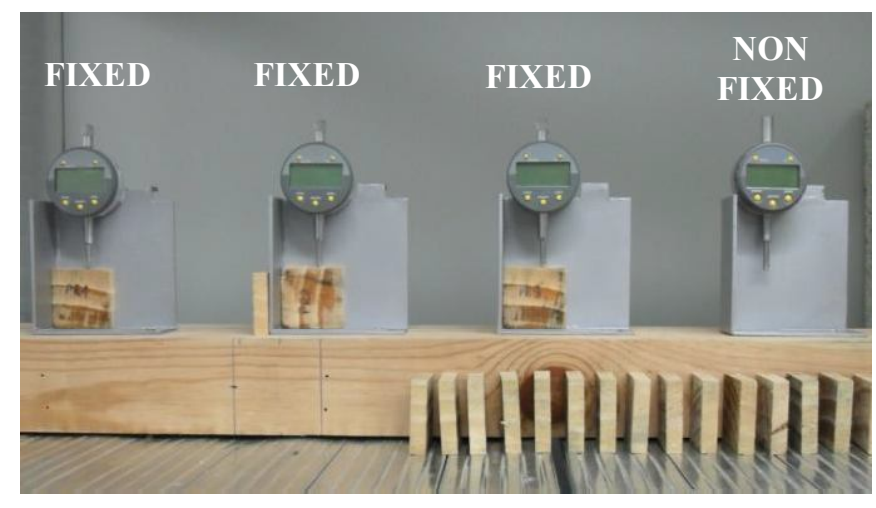

Fig. 1: Fixed and non-fixed measurement systems. 


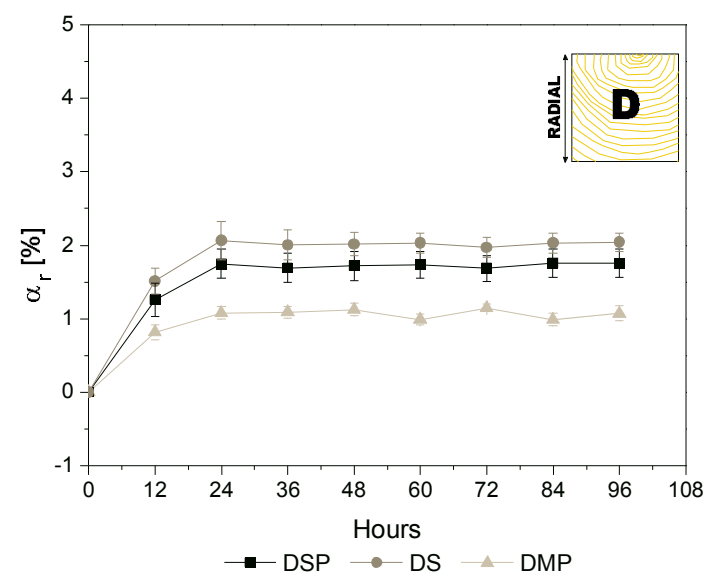

(a)

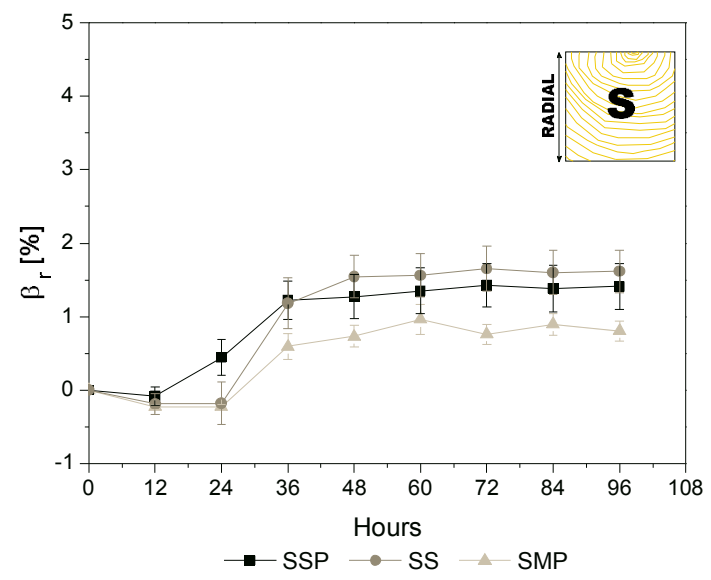

(c)

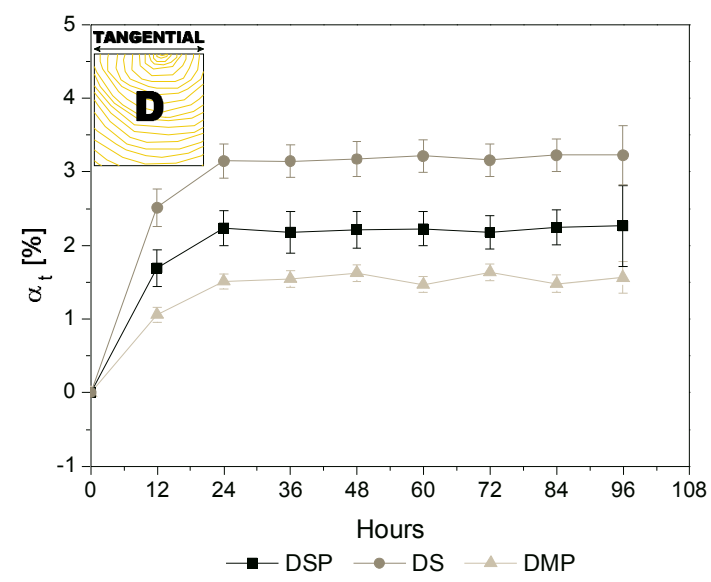

(b)

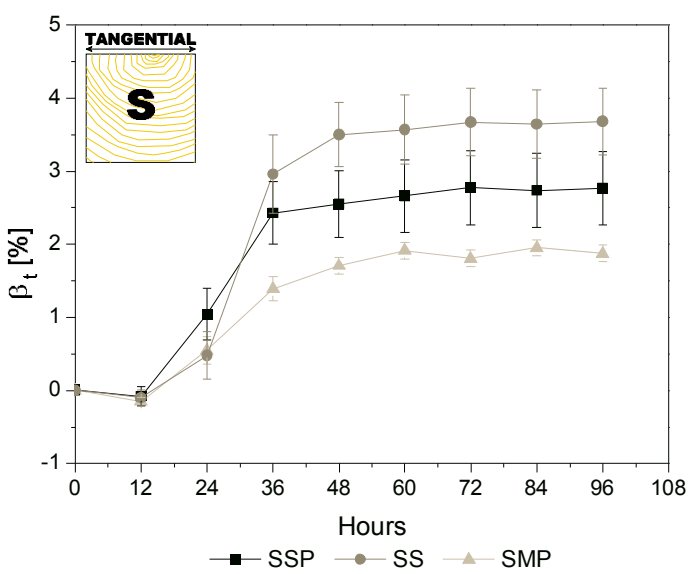

(d)

SMP - Saturated Maritime Pine; SS - Saturated Spruce; SSP - Saturated Scots Pine; DMP - Dried Maritime Pine; DS - Dried Spruce; DSP - Dried Scots Pine

Fig. 2: Linear shrinkage $(\beta)$ and swelling $(\alpha)$ in time in radial and tangential directions of larger experimental campaign with standard deviation bars. (a) dried specimens [D] in radial direction; (b) dried specimens $[\mathrm{D}]$ in tangential direction; (c) saturated specimens $[\mathrm{S}]$ in radial direction (d) saturated specimens $[\mathrm{S}]$ in tangential direction 


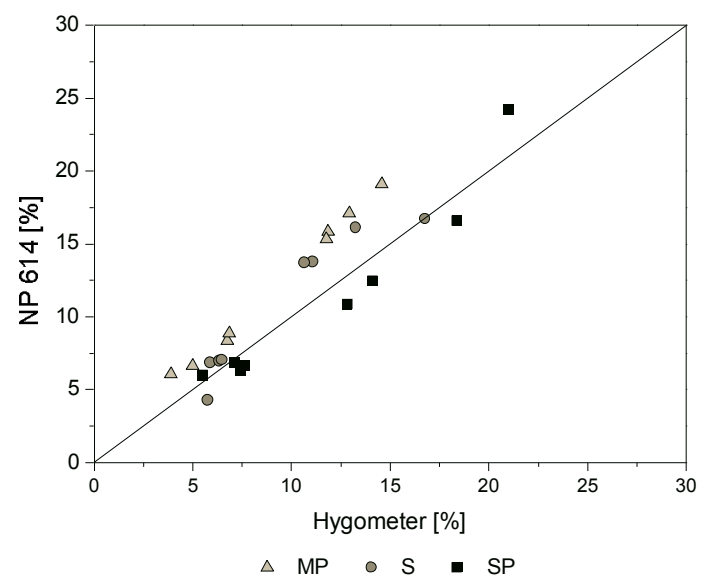

MP - Maritime Pine; S -Spruce; SP - Scots Pine

Fig. 3: Reliability of hygrometer when compared with weighing (method suggested in [19]). 


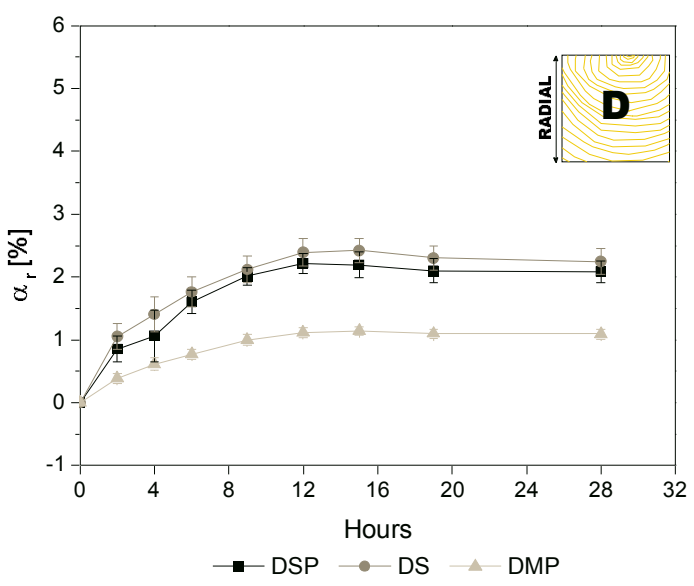

(a)

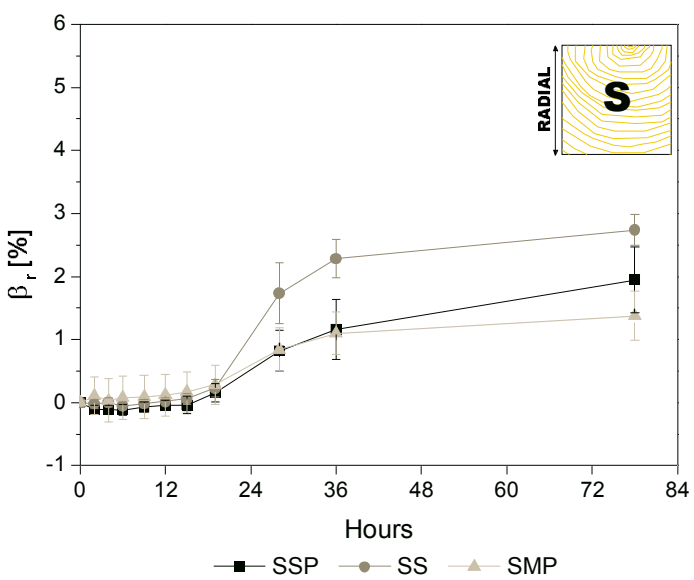

(c)

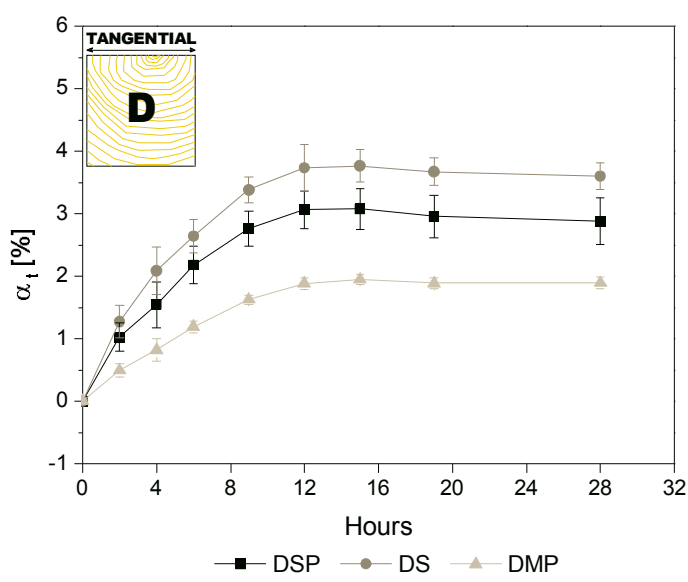

(b)

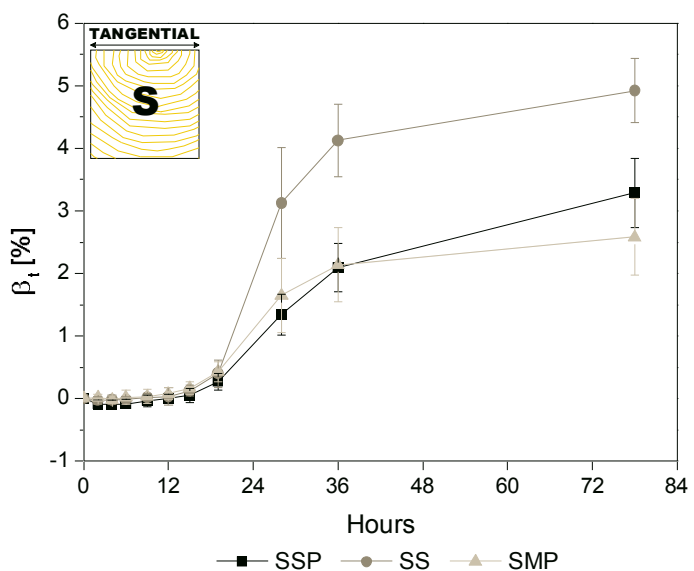

(d)

ODMP - Only Dried Maritime Pine; ODS - Only Dried Spruce; ODSP - Only Dried Scots Pine; SDMP - Saturated and Dried Maritime Pine; SDS - Saturated and Dried Spruce; SDSP - Saturated and Dried Scots Pine.

Fig. 4: Linear Shrinkage $(\beta)$ and Swelling $(\alpha)$ in time in radial and tangential directions calculated during smaller experimental campaign, with standard deviation bars. (a) only dried specimens [D] in radial direction; (b) only dried specimens [D] in tangential direction; (c) saturated and dried specimens when saturated $[\mathrm{S}]$ in radial direction (d) saturated and dried specimens when saturated $[\mathrm{S}]$ in tangential direction 


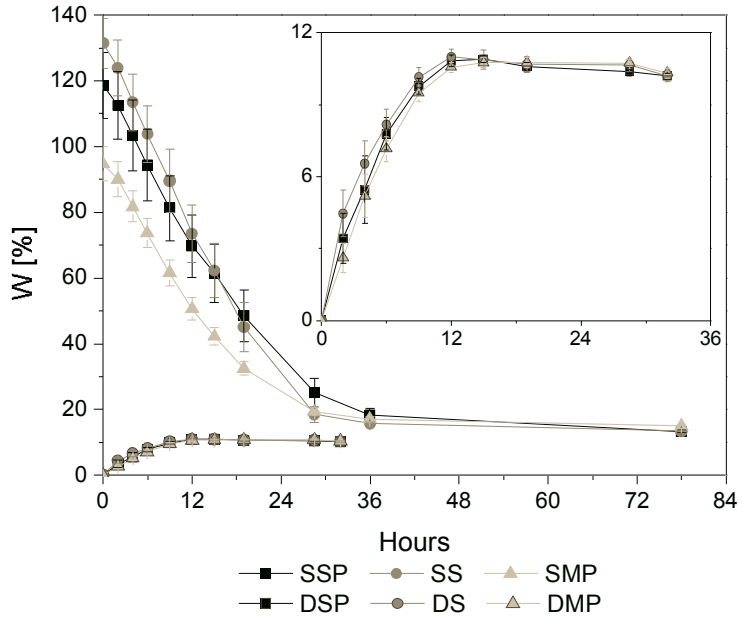

(a)

SdMP - Saturated and Dried Maritime Pine when Saturated ; SdS - Saturated and Dried Spruce when Saturated; SdSP - Saturated and Dried Scots Pine when Saturated; sDMP - Saturated and Dried Maritime Pine when Dried; sDS - Saturated and Dried Spruce when Dried ; sDSP - Saturated and Dried Scots Pine when Dried

Fig. 5: Moisture content (W) and its relation with time during smaller experimental campaign 


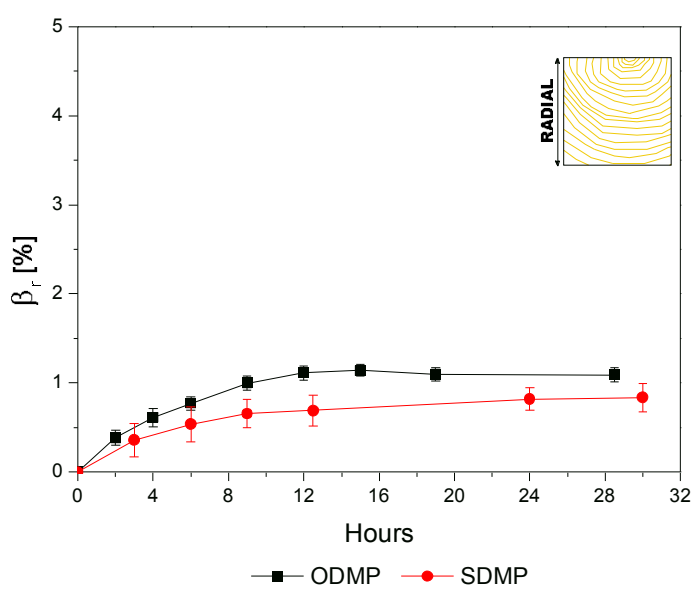

(a)

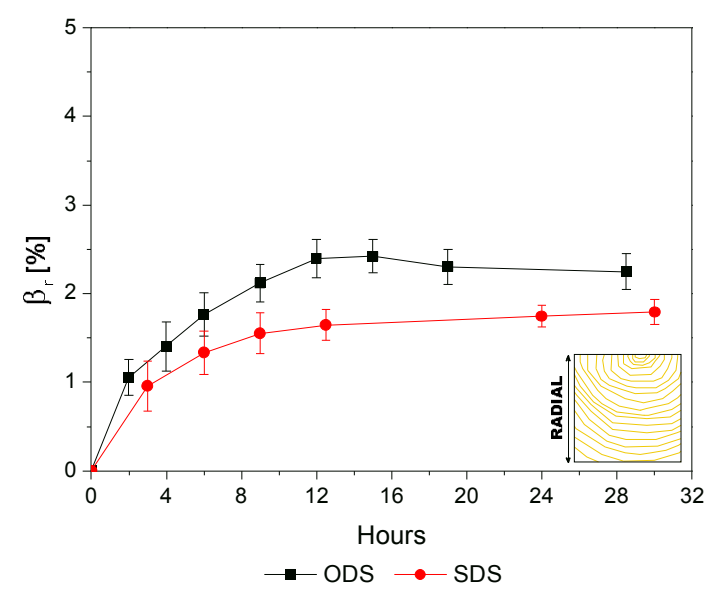

(c)

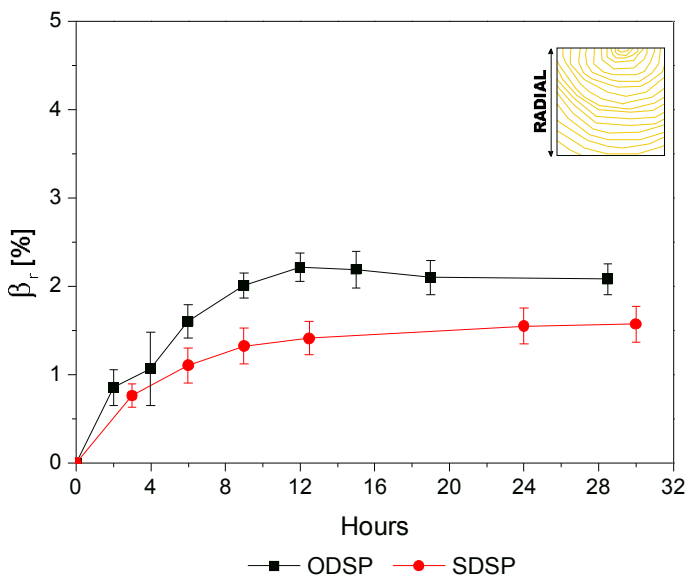

(e)

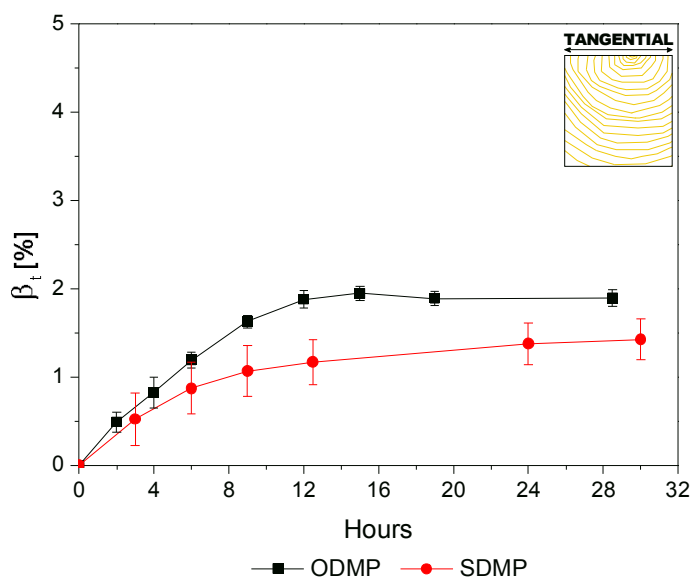

(b)

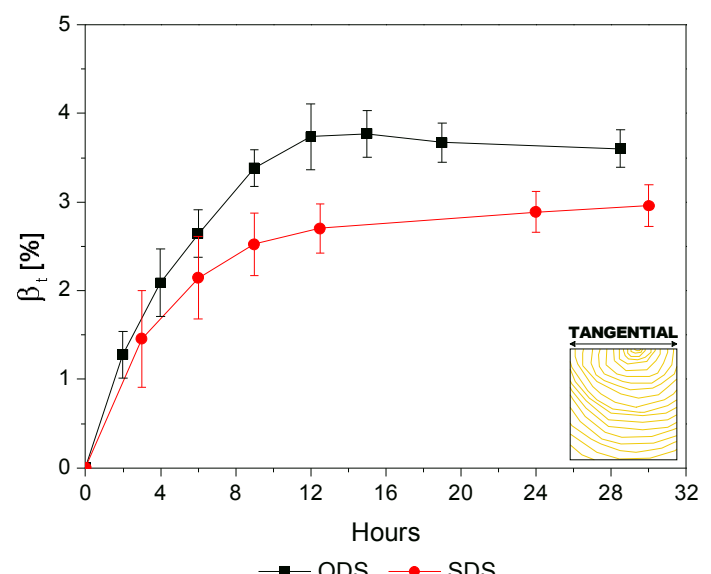

(d)

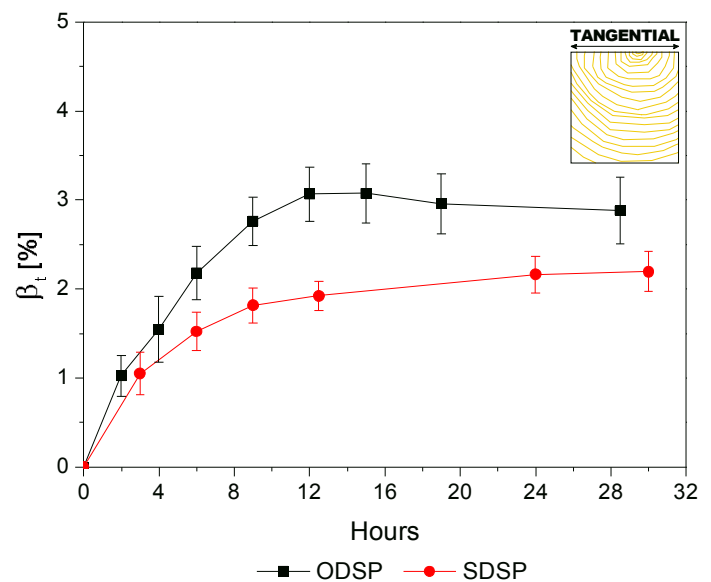

(f)

SDMP - Saturated and Dried Maritime Pine; SDS - Saturated and Dried Spruce; SDSP - Saturated and Dried Scots Pine; ODMP Only Dried Maritime Pine; ODS - Only Dried Spruce; ODSP - Only Dried Scots Pine

Fig. 6: Evolution of linear swelling in time representing loose of elastic capacity of wood when dried after saturation. (a) Maritime Pine in radial direction; (b) Maritime Pine in tangential direction; (c) Spruce in radial direction; (d) Spruce in tangential direction; (e) Scots Pine in radial direction; (f) Scots Pine in 